Revista Aspas

ppgac - USP

Especial

\title{
MOVIMENTO A DANÇA SE MOVE DIANTE DE RETROCESSOS DAS POLÍTICAS CULTURAIS ESTRUTURANTES
}

DANCE MOVES MOVEMENT IN THE FACE OF STRUCTURANT CULTURAL POLICIES SETBACKS

MOVIMIENTO LA DANZA SE MUEVE ANTE RETROCESOS DE LAS POLÍTICAS CULTURALES ESTRUCTURANTES

\section{MOUVEMENT LA DANSE SE MEUT FACE AUX ÉCHECS DES POLITIQUES CULTURELLES STRUCTURANTES}

Helena Bastos e Vanessa Macedo

Helena Bastos

Co-Diretora do Grupo Musicanoar, fundado em 1992. Bailarina e coreógrafa. Professora na graduação e pós-graduação do

Departamento de Artes Cênicas/CAC da ECA da USP. Chefe de Departamento (2011-2014) e Coordenadora de Curso (2017-2019). Credenciada no PPGAC da ECA/USP.

E-mail: helenahelbastos@gmail.com

Vanessa Macedo Diretora da Cia Fragmento de Dança, de São Paulo-SP, fundada em 2002. Coreógrafa, bailarina e pesquisadora. Bacharel em Direito (UFRN), mestre em Artes (UNICAMP) e doutora em Artes Cênicas

(ECA-USP). 


\section{Resumo}

"O que veio primeiro: arte ou mercado financeiro?" (Gielen, 2015). Nesta provocação está implícito que investir é uma atividade criativa. Dimensões úmidas e planas vão se constituindo e povoando cada vez mais nosso modo de lidar com criação. Os atuais modos de aglutinação praticam outros tipos de cooperação que se transformam em coletivos temporários. Desejamos investigar tais fenômenos através das formas de comunicação que inventam e da ambivalência e da dissimetria que os constituem. Dessas perspectivas, propomos uma discussão no cruzamento entre três eixos: Movimento a Dança se Move, AtoFórum contra a criminalização da ArteCultura e capitalismo criativo. Autores como Giorgio Agamben e Pascal Gielen são norteadores nessa discussão.

Palavras-chaves: AtoFórum; Capitalismo Criativo; Políticas Culturais; Movimento a Dança se Move.

\section{Abstract}

"What came first: art or financial market?" (Gielen, 2015). In this provocation it is implied that investing is a creative activity. Humid and flat dimensions are becoming and increasingly populating our way of dealing with creation. The present modes of agglutination practice other types of cooperation that become temporary collectives. We wish to investigate such phenomena through the forms of communication they invent and the ambivalence and dissymmetry that constitute them. From these perspectives, we propose a discussion at the crossroads between three axes: Dance Moves Movement, AtoFórum against the criminalization of ArteCultura and creative capitalism. Authors like Giorgio Agamben and Pascal Gielen are guiding in this discussion.

Keywords: AtoFórum; Creative Capitalism; Cultural Policies; Movement to Dance moves.

\section{Resumen}

"¿Qué vino primero: arte o mercado financiero?" (Gielen, 2015). En esta provocación está implícito que invertir es una actividad creativa. Las dimensiones húmedas y planas se van constituyendo y poblando cada vez más nuestro modo de hacer frente con la creación. Los actuales modos de aglutinación practican otros tipos de cooperación que se transforman en colectivos temporales. Deseamos investigar tales fenómenos a través de las formas de comunicación que inventan y de la 
ambivalencia y disimetría que los constituyen. De estas perspectivas, proponemos una discusión en el cruce entre tres ejes: Movimiento la Danza se mueve, AtoFórum contra la criminalización del ArteCultura y el capitalismo creativo. Autores como Giorgio Agamben y Pascal Gielen son orientadores en esta discusión.

Palabras claves: AtoFórum; Capitalismo Creativo; Políticas culturales; Movimiento la Danza se mueve.

\section{Résumé}

"Qu'est-ce qui est arrivé en premier: l'art ou le marché financier?" (Gielen, 2015). Dans cette provocation, il est implicite que l'investissement est une activité créative. Les dimensions humides et plates sont en train de devenir et peuplent de plus en plus notre manière de traiter avec la création. Les modes actuels d'agglutination pratiquent d'autres types de coopération qui deviennent des collectifs temporaires. Nous souhaitons étudier ces phénomènes à travers les formes de communication qu'ils inventent et l'ambivalence et la dissymétrie qui les constituent. À partir de ces perspectives, nous proposons une discussion à la croisée de trois axes: Mouvement La Danse Se Meut, AtoFórum contre la criminalisation de l'ArteCultura et le capitalisme créatif. Des auteurs comme Giorgio Agamben et Pascal Gielen guident cette discussion.

Mots-clés: AtoFórum; Capitalisme Créatif; Politiques Culturelles; Mouvement à la danse se déplace.

Há muitas questões implicadas entre dança contemporânea e seus modus operandis frente a uma política cultural que dissemina, cada vez mais, um pensamento plano em que as lógicas de aglutinação vão acontecendo via programas de incentivos públicos. São encontros que se dão com data marcada de começo e fim, isto é, planos programados para existirem enquanto cumprem o prazo de projetos contemplados. O diretor do Centro de Artes em Sociedade da Universidade de Groningen (Holanda), Pascal Gielen, nos introduz o ator-rede. "Um mundo plano e úmido, que vê a si mesmo como uma rede, pressupõe características específicas e faz certas demandas para as pessoas que estão flutuando sobre ele" (GIELEN, 2015, p.39). 
Ao apresentarmos dessa forma crítica tais estratégias, não pretendemos desprezar essas iniciativas, mas expor as contradições que vão se replicando nas lógicas de editais. Alguns editais e programas de cultura são conquistas que vieram de lutas, por entender que determinada arte no Brasil não é mercadológica. Lembramos do Programa de Fomento à Dança na cidade de São Paulo', batalha importante para criar outros deslocamentos em dança sublinhando um perfil: o do artista criador (intérprete), autor e pesquisador. Havia na sua elaboração e criação enquanto programa a preocupação e necessidade em demarcar o termo contemporâneo, por isso, dança contemporânea. Foi uma estratégia de legitimar e dar visibilidade a uma natureza de dança que sublinhava a conexão imediata entre processo e produto na mesma escala temporal. Depois de uns cinco anos de existência, surgem contradições em virtude da própria permanência, sucesso e relevância deste programa. Passados dez anos, essas contradições se acentuaram, e muito. Vê-se sucessivos dissensos entre os artistas da dança, culminando, inclusive, na discussão sobre a necessidade ou não de alteração da Lei. No tempo, evidencia-se uma demanda que antes não se previa, isto é, naquilo em que se reconhecem avanços, também se percebem contradições. Enfim, o Programa cumpre um papel, mas suas irrigações vão nos deslocando em horizontes não previstos.

Pertencemos a uma temporalidade em que a mobilidade e as redes sociais se conectam de modo incisivo no nosso cotidiano, quando nos propomos a fazer e pensar arte. Dessa e nessa perspectiva enquanto artistas, povoamos espaços em que a indústria criativa cada vez mais gera uma fricção contínua, tensionando o modo como nos implicamos em nossa produção artística. Aqui abordamos o artista do corpo com ênfase em dança, mas contaminado de questões da performance e do teatro. É deste tecido, irrigado de secreções entre muitos moveres que este artista em dança se organiza e se mobiliza. Moveres (BASTOS, 2017) é uma palavra

\footnotetext{
${ }^{1}$ Lei Municipal no 14.071, de 18 de outubro de 2005 que tem como escopo fomentar trabalhos continuados de pesquisa em dança contemporânea.
} 
redimensionada, tem a ver com ação, mover com propósitos. Neste caso, são moveres com propósitos em dança.

Desejamos apontar como os campos da economia criativa e da criação artística vêm se implicando a partir de um momento muito específico na história da América Latina. Foi a derrubada do governo democraticamente eleito de Salvador Allende, em um golpe militar, em que o "conluio entre as elites financeiras dos EUA e o novo regime ditatorial de Pinochet pôs em ação aquilo que Naomi Klein chamou de 'A Doutrina do Choque"'?2

Ao recordarmos do golpe de Augusto Pinochet (1915-2006) sublinhamos que, segundo afirma a ativista Naomi Klein em entrevista ao Instituto Humanitas Unisinos - IHU, "A Doutrina do Choque" como todas as doutrinas é uma filosofia de poder:

\begin{abstract}
É uma filosofia sobre como conseguir seus próprios objetivos políticos e econômicos. É uma filosofia que sustenta que a melhor maneira, a melhor oportunidade para impor as ideias radicais do livre-mercado é no período subsequente ao de um grande choque. Esse choque pode ser uma catástrofe econômica. Pode ser um desastre natural. Pode ser um ataque terrorista. Pode ser uma guerra. Mas a ideia é que essas crises, esses desastres, esses choques abrandam a sociedades inteiras. Deslocam-nas. Desorientam as pessoas. E abre-se uma 'janela' e a partir dessa janela se pode introduzir o que os economistas chamam de 'terapia do choque econômico'. ${ }^{3}$ (KLEIN, 2007)
\end{abstract}

Vai-se afirmando que a história do livre-mercado contemporâneo foi escrita em choques, sendo a indução da violência extremamente benéfica para as corporações. Ao trazer o golpe de Pinochet entendemos como alianças de um pensamento econômico neoliberal foi se estruturando na América Latina. Ainda Klein:

\footnotetext{
Depois da eleição de Salvador Allende, a eleição de um socialista democrático, em 1970, houve um complô para derrubá-lo. Nixon disse genialmente: "Que a economia grite". E o complô teve numerosos elementos, embargos, etc. e finalmente o apoio para $o$ golpe de Pinochet em setembro de 1973. Escutamos muito falar

${ }^{2}$ https://acasadevidro.com/2016/01/31/capitalismo-a-la-pinochet-naomi-klein-revela-osmeandros-da-doutrina-do-choque/)

${ }^{3}$ http://www.ihu.unisinos.br/176-noticias/noticias-2007/562784-a-doutrina-do-choque-o-temado-novo-livro-da-ativista-naomi-klein
} 
nos 'Chicago Boys' no Chile, mas não sabemos detalhes sobre o que foram na realidade. O que faço no livro é contar esse capítulo da história. (...) Em 11 de setembro de 1973, enquanto os tanques rodavam pelas ruas de Santiago e o palácio presidencial ardia e Salvador Allende era morto, um grupo dos assim chamados 'Chicago Boys', assumia o controle da economia. Economistas chilenos que haviam sido levados para a Universidade de Chicago para estudar com bolsas do governo dos EUA como parte de uma estratégia deliberada para orientar a direita latino-americana. ${ }^{4}$ (KLEIN, 2007)

Achamos importante indicar o contexto de como ideias de livre mercado começam a dominar o mundo. Nessa varredura, o Chile desponta como um protagonista nesta exportação de modelo econômico para o resto do mundo.

Não pretendemos fazer aqui uma análise econômica, mas localizar onde e como o pensamento neoliberal econômico - de livre mercado - vai se estruturando e se irradiando para outras partes do mundo, além do que, como este modelo econômico de operar vai contaminando também os modos de produção em artes. Retomamos Gielen quando nos alerta:

\begin{abstract}
A crise financeira é baseada em um forte 'processo de ficção', no qual o dinheiro se destaca da matéria (ouro) e especialmente do trabalho e da economia real de produção. Esta desconexão torna altamente virtuais as moedas e as trocas econômicas, como se elas dependessem de fórmulas abstratas. Quando as transações monetárias se tornam uma fórmula de matemática abstrata, que dificilmente alguém entende, gera-se uma atividade artística na qual a fé coletiva suporta um mundo altamente virtual. (GIELEN, 2015, p. 16)
\end{abstract}

Vai-se evidenciando como o campo da economia passa a operar e regular os mercados. E aqui identificamos palavras reconhecidas do campo das artes que vão sendo capturadas nos modus operandis da economia. É ainda Gielen que nos provoca: "O que veio primeiro: arte ou mercado financeiro?" (GIELEN, 2015, p.17). Gielen nos interpela quando aponta: "o paralelo nos diz que o chamado mundo sólido das finanças é, na realidade, fundado sobre flexíveis interpretações culturais. Investir sempre foi considerado uma atividade criativa". (GIELEN, 2015, p.17)

Percebemos que em alguma medida o mercado financeiro vai

${ }^{4}$ Idem 
capturando palavras que a princípio são jargões do campo das artes, porém o inverso se dá também. Hoje qualquer artista tem que apresentar um CNPJ para a inscrição de projeto. Palavras e termos como rede, flexibilidade, criatividade, proponente, contrapartida e economia criativa escorrem de um campo a outro. De algum modo, vão se pontuando crises em crenças.

Crises nos mobilizam em ações, mas crenças nos paralisam, pois se transformam em verdades absolutas, impondo restrições, como se não coubessem questionamentos ou outros desdobramentos possíveis. Entre crença e religião cabem poucas diferenças. Porém, uma crise provoca a capacidade de 0 ambiente criar condições de transformações, se resolvemos confrontá-la. Um projeto artístico pode apresentar tal capacidade, organizado enquanto ação de confronto na crise e ao mesmo tempo de expansão de um campo artístico. Dependendo da crise, a mobilidade de enfrentamento surge como agrupamentos, que de forma pontual se organizarão para expor determinadas contradições.

Esse panorama inicial nos parece contribuir para a compreensão de algumas transformações nos modos de criação, produção e difusão das artes do corpo. A partir dos anos 90, vimos despontar diferentes formas de aglutinação, desencadeando outras reflexões sobre poder e política. Desse contexto, surgiu a necessidade de desenvolver estratégias, tanto na criação do artista em cena quanto na sua necessidade de propor circuitos entre parceiros para uma atuação coletiva, mesmo que pontualmente, em um momento específico. Nesse fluxo, ao explorar a cena contemporânea a partir de seus processos políticos de criação e de seus processos políticos de organização, percebemos que no lugar da comunhão e da posse, os atuais modos de aglutinação praticam outros tipos de cooperação - movimentos de mobilização social que se transformam em coletivos temporários e modos singulares de produção artística pautados em outras lógicas de organização. Desejamos investigar quais formas de comunicação inventam, dentro da ambivalência e da dissimetria que constituem tais fenômenos, especificamente olhando para o Movimento a Dança se Move - uma aglutinação estético política entre criadores de dança da cidade de São Paulo. Desde 2011, reúnem-se em distintos pontos da cidade paulistana, a 
fim de discutir políticas culturais para a dança e, especialmente nos últimos dois anos, tem atuado contra o desmonte da arte num alinhamento explícito que vai da cidade de São Paulo, perpassa o Estado e chega ao Governo Federal.

Dessas perspectivas, o Movimento a Dança se Move - frente ao retrocesso das políticas culturais estruturantes envolvendo programas de formação, criação e difusão da arte e da cultura da cidade de São Paulo, entre outros fatos que dizem respeito às artes no Brasil - atuou numa série de atos, no ano de 2017, e resolveu pontuar, em dezembro deste mesmo ano, com uma manifestação que evidenciasse nossa indignação. Antes de descrever sobre o AtoFórum realizado, exporemos primeiramente como surge o Movimento a Dança se Move.

\section{Movimento a Dança se Move - fluxos de encontros entre desencontros}

No ano de 2011, a Cooperativa Paulista de Dança ${ }^{5}$ e o Movimento Mobilização Dança ${ }^{6}$ davam início ao que seria a gênese do Movimento a Dança se Move - a organização de um seminário, nos dias 27 e 28 de maio, na Câmara Municipal de São Paulo, chamado "A Dança se Move: Debates sobre as Políticas Públicas para a Cidade de São Paulo". Foram um total de 11 horas de discussões, organizadas durante esses dois dias, e tivemos como principais pautas: os princípios e critérios norteadores no processo de criação e consolidação da Lei de Fomento à Dança; a necessidade de elaboração de novos programas para a dança nas esferas municipal, estadual e federal; a discussão sobre a necessidade de um coordenador de dança dentro da Secretaria municipal de Cultura.

Esse foi o início de uma série de outros seminários, ocupando a Câmara Municipal, nos anos de 2011 e 2012. Além das convocatórias gerais

\footnotetext{
${ }^{5}$ Fundada em São Paulo, no ano de 2005, a Cooperativa Paulista de Dança é uma instituição de caráter jurídico-artístico que nasceu do interesse de bailarinos e coreógrafos de se organizarem como entidade representativa da categoria.

${ }^{6}$ Organização coletiva e apartidária de artistas da dança contemporânea, surgido no ano de 2002, em São Paulo, que teve como uma das suas principais conquistas a Lei de Fomento à Dança. http://mobilizacaodanca.blogspot.com/
} 
para que todos os interessados se reunissem no debate de políticas culturais, grupos de trabalhos se reuniam no desenvolvimento de três programas específicos para a dança paulistana, contemplando: artistas e grupos com mais de 15 anos de trajetória; jovens artistas; circulação e difusão de trabalhos artísticos. Os encontros eram chamados de $A$ Dança se Move, ainda não se falava em movimento. Foi um período muito rico para a dança da cidade no sentido de aglutinar profissionais muito diversos em suas pesquisas e produções. Tanto no sentido territorial quanto temporal. Ali se juntaram diversas gerações e segmentos da dança contemporânea em discussões assíduas e com quórum expressivo.

Os materiais escritos sobre esses encontros constam em nossos arquivos pessoais e, em grande parte, foram disponibilizadas no blog do $A$ Dança se Move ${ }^{7}$. Mas essa memória exige uma pesquisa mais específica, pois há momentos de excessiva demanda em que não se consegue registrar a quantidade de ações realizadas, tanto por se tratar de uma organização informal, na qual os participantes se alternam em funções pouco claras, quanto pelo tempo e dedicação que exigem esse tipo de atividade. Por essa razão há registros esparsos e informações desatualizadas tanto no blog, como na página criada no Facebook ${ }^{8}$.

Um ano após o primeiro seminário, discutia-se sobre como referendar as decisões tomadas em assembleias, considerando que esses chamamentos eram feitos pela Cooperativa Paulista de Dança e pelo Movimento Mobilização Dança. Nascia um outro tipo de organização com natureza própria, frequentada por profissionais que não necessariamente pertenciam àquelas entidades responsáveis pelo chamamento. Sentia-se, portanto, a necessidade de se firmar uma nova entidade representativa. Pelos registros que temos, foi no manifesto de 23 junho de 2012 que se vê, pela primeira vez, o Dança se Move assinando como movimento. Tratava-se de um manifesto de repúdio em relação ao processo de renovação dos colegiados setoriais. Os artistas da dança afirmavam que a então gestão do

\footnotetext{
${ }^{7}$ http://dancasemove.blogspot.com/

${ }^{8} \mathrm{https} / / / \mathrm{www}$. facebook.com/ADancaSeMove/
} 
MinC "não demonstrava real disposição de diálogo e de uma construção participativa nas políticas culturais".

Também é importante mencionar que nesse mesmo momento, o Mobilização Dança já não se reconhecia mais como um movimento ativo e foi um período de transição para alguns artistas que atuavam nessa organização. Por isso, encontraremos relatos afirmando que o Dança se Move, em parte, é uma continuação do Mobilização Dança. Trata-se de um movimento civil sem registro formal, que atua como organização de trabalhadores da dança interessados em discutir e encaminhar demandas para o avanço das políticas culturais, nos âmbitos municipal, estadual e federal.

Houve fases de muita adesão, como em seu início, e outras de brigas internas, exposição, fragilidades. Especialmente, entre os anos de 2015 e 2016, outros movimentos surgiram na cidade e se instauraram períodos de conflitos e discussões sobre legitimidade e representatividade. Quando o $A$ Dança se Move assina como tal, quais artistas e grupos, de fato, estão ali representados e responsáveis pelas decisões? Passamos a sentir a necessidade, portanto, de não apenas mencionarmos o movimento, mas colocarmos por extenso o nome dos artistas e núcleos envolvidos. É a própria informalidade dessas organizações que as fazem tão democráticas quanto precárias e questionáveis em muitas situações. Percebemos fases flutuantes. Há artistas que permanecem desde o seu início, mas não são muitos. O que se vê é o que o próprio nome nos diz - um movimento que, no ato de mover, reconfigura-se, adaptando-se a novas situações. Algumas vezes silencia. Outras assume com braveza.

Reconhecidas essas flutuações, é importante mencionarmos a participação efetiva do $A$ Dança se Move numa série de ações: a alteração do tempo de execução dos projetos da Lei de Fomento à Dança para a Cidade de São Paulo de um para dois anos; a regulamentação da Profissão de bailarino - Projeto de Lei Complementar 644/2015, de autoria do Senador

\footnotetext{
${ }^{9} \mathrm{O}$ "Manifesto de repúdio e boicote ao processo de eleição para a nova composição dos colegiados setoriais" foi elaborado na FUNARTE/SP por ocasião da 9a reunião "A Dança se Move", em junho de 2012. Disponível em: http://dancasemove.blogspot.com/2012/07/?m=0. Acesso em 8 jul. 2018.
} 
Walter Pinheiro; a aposentadoria Especial para bailarinos - Projeto Lei complementar 190/2015, de autoria do Deputado Federal Carlos Zarattini; o desenvolvimento de ações e atos, no ano de 2017, no início da gestão do então prefeito João Dória, relacionadas aos desmonte dos Programas Culturais Da cidade de São Paulo e de situações ligadas ao Tribunal de Contas do Município e ao orçamento para cultura.

Muitos dos que aqui destacamos foram e são atos realizados em parceria com a Cooperativa Paulista de Dança. No entanto, pode-se dizer que, hoje, o Movimento a Dança se Move é um movimento autônomo que se organiza sem cargos e funções e que mantém encontros regulares a partir do encontro de pessoas que compartilham interesses comuns em relações às políticas culturais relacionadas à dança.

Figura1: Encontro do Movimento a Dança se Move - Centro de Referência da Dança.

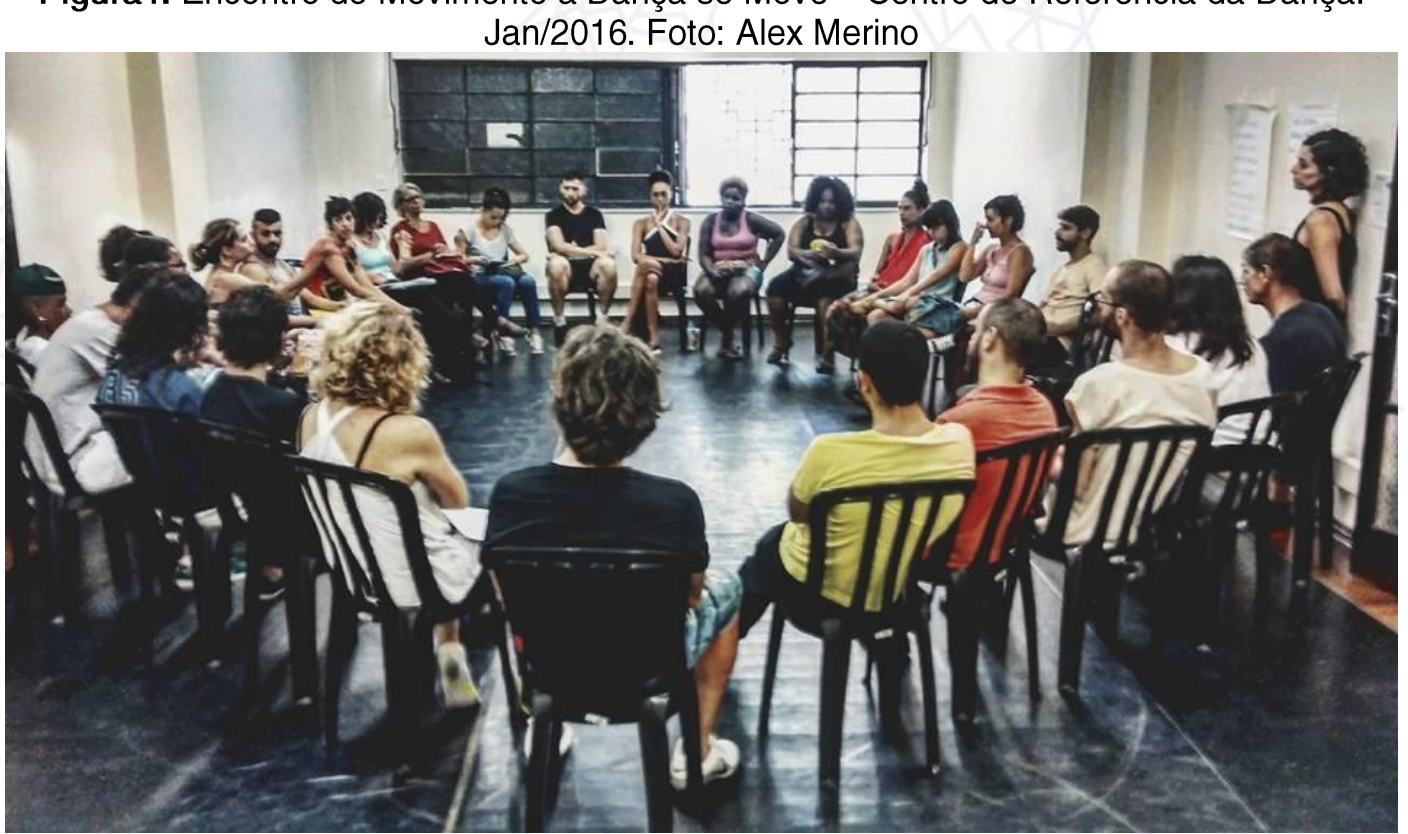

Fonte: Facebook a dança se move

São destes moveres que o Movimento a Dança se Move se constitui. Não à toa fomos levados a pensar e produzir um AtoFórum que demarcasse toda a nossa indignação. Nesse caso, agregamos muita gente, gente que insiste em afastar ideias de crenças na produção de gestos imóveis, imexíveis. Nossa própria história evolutiva nos devolve que quem fica preso no tempo, fica lá, sozinho. Enquanto vivos, o próprio nome do Movimento dá 
uma pista, a dança se move, se move como um rio, que ocasionalmente é desviado por uma pedra ou uma brisa. Escorre no tempo.

\section{AtoFórum contra a criminalização da ArteCultura}

Surge como uma necessidade de pontuar 2017 frente a uma série de ataques ligados à cultura, produzindo retrocessos em várias frentes artísticas. Esta é uma leitura construída entre vários colegas que participaram e participam do Movimento a Dança se Move. Precisávamos encerrar aquele ano com um ato potente, apesar de exauridos.

Figura 2: AtoFórum contra a criminalização da ArteCultura - TUSP/SP - Dez/2017

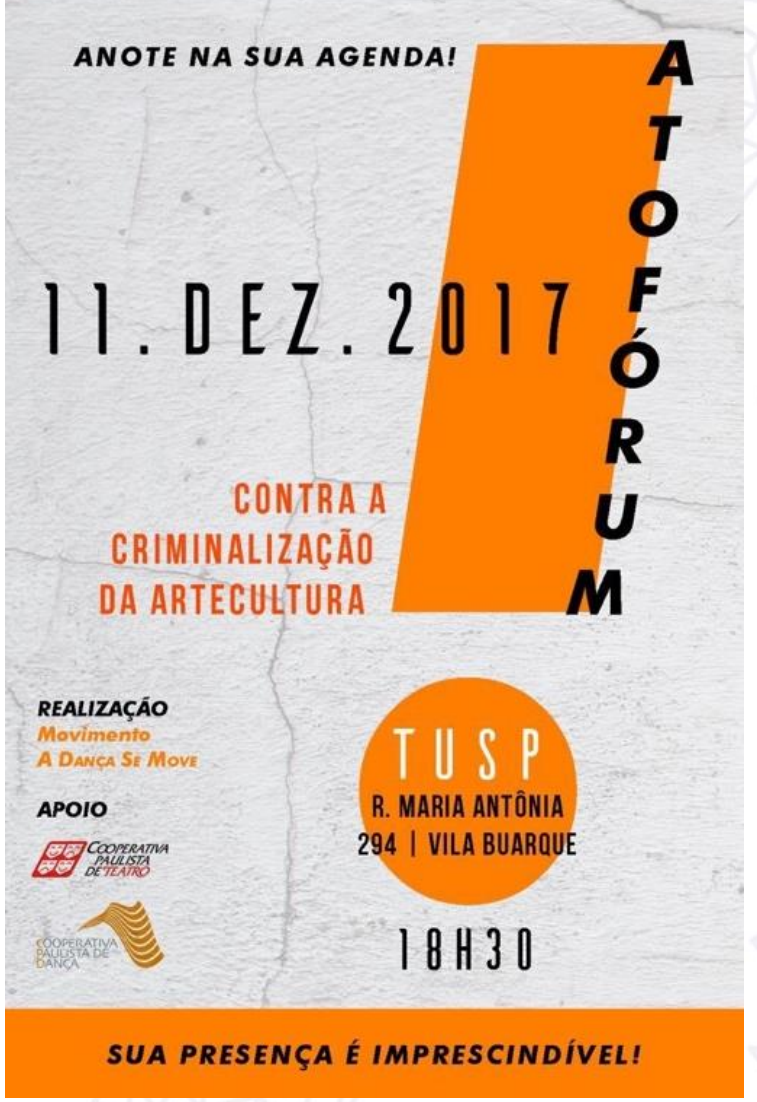

Fonte: Flyer do Movimento a Dança se Move

Muitas hipóteses foram levantadas como resposta aos recentes ataques sofridos pelos artistas e o "AtoFórum contra a criminalização da ArteCultura", protagonizado pelo Movimento a Dança se Move, levou ao TUSP, no dia 11 de dezembro de 2017 todo o seu desejo de dizer não à 
censura, ao desmonte e ao movimento de criminalização dos artistas e suas obras.

O Ato foi motivado, inicialmente, como resposta às matérias veiculadas pelo jornal a Folha de $S$. Paulo que atacavam a imagem da Cooperativa Paulista de Dança e do Programa Municipal de Fomento à Dança. Mas não era só a dança, nem a cidade de São Paulo que sentiam o esmagamento profundo de tantos espaços construídos a duras penas. Em diversas cidades do Brasil viveu-se a censura. Políticos, Ministério Público e Instituições Culturais tomaram parte na contenda absurda que relacionou arte e pedofilia. Programas de formação artística foram completamente desestruturados.

$\mathrm{Na}$ imbricação entre arte e pedofilia, um fato marcou especialmente a dança. Destacamos a perseguição ao artista Wagner Schwartz que abriu o 35. Panorama de Arte Brasileira, no Museu de Arte Moderna (MAM) de SP com a performance "La Bête"10, uma inspiração da obra Bichos, de Ligia Clark. A performance se dava dentro das instalações do museu. Schwartz se apresentava nu e exposto à manipulação da plateia, que poderia colocar o seu corpo em diversas posições. Não tinha nenhuma conotação sexual, era apenas um corpo sendo corpo. No público presente havia também uma criança que o manipulou sob o consentimento de sua mãe e, após um fragmento desse gesto interativo ser lançado na internet, o artista foi acusado injustamente de pedófilo. Em razão disso, artista, mãe e museu tiveram que enfrentar abertura de inquérito pelo Ministério Público de São Paulo e convocação para prestarem depoimentos na CPI de maus-tratos contra crianças e adolescentes. Frente à polêmica, o então prefeito da cidade de São Paulo, João Dória, fez uma declaração nas redes sociais: "Não pode, em nome dessa liberdade, permitir que uma cena libidinosa, que estimula uma relação artificial, condenada e absolutamente imprópria seja colocada'".

Mesmo que, mais tarde, o Ministério Público tenha pedido arquivamento da investigação, o estrago foi grande, pois o fato também

\footnotetext{
${ }^{10} \mathrm{https} / / /$ brasil.elpais.com/brasil/2018/02/12/opinion/1518444964_080093.html

${ }^{11}$ Disponível em https://www.youtube.com/watch?v=2fkKQaKUjZQ
} 
produziu muitas ameaças de morte ao artista. Hoje, ele tem dificuldades de convites para suas apresentações artísticas no Brasil. Após um tempo recluso, Schwartz se manifestou no jornal El Pais, em entrevista a Eliane Brum, do qual extraímos alguns fragmentos:

\begin{abstract}
Precisamente, precisei de dois meses e meio para sair do trauma. Era muito difícil falar próximo aos dias dos ataques. As palavras fugiam e ainda me faltam. [...] Quando se dirigem a mim como o "rapaz nu" ou como o "homem nu", ao invés de "o artista Wagner Schwartz" ou "Wagner Schwartz, autor de La Bête", a ação performativa é eliminada e minha existência como artista também desaparece. [...] No discurso moralizante não existe preocupação com a democracia. Os que não fazem parte do rebanho precisam ser dele separados, e, para tal, justificam-se atos de violência que nunca poderiam ser justificados ${ }^{12}$.
\end{abstract}

Retomando ao AtoFórum, no mesmo mês em que nos organizávamos, no final de 2017, a Revista Cult lançava seu dossiê com o seguinte tema: "Arte Sob Coerção: moralismo privado no Espaço Público". Em sua abertura, Márcia Tiburi afirma que os jogos de poder envolvendo as artes fazem parte da história, mas chama a atenção para o atual momento no Brasil, colocando lado a lado dois termos que se opõem por definição: arte e autoritarismo.

O caráter autoritário tem história e geografia, desenvolve-se no tempo e no espaço. Ele se manifesta em contextos os mais diversos, em nível pessoal e coletivo. Assim como a arte. Pessoas e instituições fomentam em determinados contextos formas antidemocráticas de expressão, cuja característica é o apagamento e o silenciamento do outro. As obras de arte tornamse insuportáveis porque dizem justamente aquilo que, por algum motivo, não se poderia dizer. A arte não se contém diante do autoritarismo (TIBURI, 2017, p. 12).

É também nesse dossiê que temos acesso a uma espécie de linha do tempo com acontecimentos que se estendem mês a mês por todo segundo semestre de 2017. O curador da mostra Queermuseu - Cartografias da diferença na arte brasileira, Gaudêncio Fidelis, escreve artigo testemunhal do que significou o fechamento abrupto da exposição que tratava de

\footnotetext{
${ }^{12}$ https://brasil.elpais.com/brasil/2018/02/12/opinion/1518444964_080093.html
} 
questões relacionadas a gênero e diversidade, patrocinada e promovida pelo Banco Santander:

\begin{abstract}
A exposição Queermuseu foi interrompida pelo Santander abruptamente trinta dias antes da data prevista de seu encerramento, em decorrência de manifestações que duraram apenas dois dias, realizadas pelo MBL, cujos integrantes ingressaram no espaço da exposição agressivamente, gerando vídeos e fotografias e produzindo uma narrativa difamatória de caráter moralista sobre o evento, baseada em apenas quatro obras de um universo de 264 que compõem a mostra. O encerramento por parte do Santander, viria então a consumar o maior dos crimes. A instituição não só interrompeu a exposição, como também consolidou o processo de censura ao reter as obras por 30 dias depois da decisão do seu término. [...] a retenção das obras caracteriza um fato extremamente grave, com diversas consequências, entre elas, os danos irreparáveis causados ao patrimônio artístico e cultural brasileiro (FIDELIS, 2017, p. 14).
\end{abstract}

O que teve início naquele 2017 permanece. Recentemente, a peça $O$ Evangelho segundo Jesus - a Rainha dos Céus, que teve apresentação cancelada em outubro daquele ano no Sesc Jundiaí por decisão judicial, foi novamente censurada no Festival Internacional de Garanhuns, agora em 2018. Em nota oficial, o prefeito da cidade declarou sua satisfação "de ver que o clamor da sociedade de Garanhuns num pedido expresso de respeito à fé cristã"13, tenha sido ouvido pelo Governo do Estado de Pernambuco. A polêmica, nesse caso, era por ser uma travesti no papel de Jesus Cristo. Ajusta-se aqui Agamben quando nos alerta: "O soberano que pode decidir sobre o estado de exceção, garante sua ancoragem na ordem jurídica" (AGAMBEN, 2004, p. 56). Neste caso, o prefeito de Garanhuns, alinhado com o Governo do Estado de Pernambuco, apesar de fora do contexto jurídico, seriam responsáveis pela decisão da suspensão da referida peça. Felizmente, dias depois da polêmica, o Ministério Público se manifestou pela reintegração da peça ao festival ${ }^{14}$.

De algum modo compreendemos que no Brasil vivemos tempos de exceção. Uma leitura é o alinhamento do judiciário com o poder público,

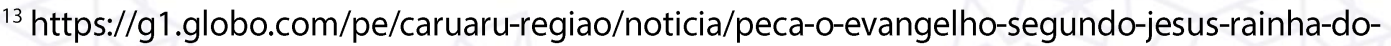
ceu-e-cancelada-no-festival-de-inverno-de-garanhuns.ghtml

${ }^{14} \mathrm{https}$ ://www.folhape.com.br/diversao/diversao/polemica/2018/07/09/NWS,74380,71,877,DIVERS AO,2330-MINISTERIO-PUBLICO-MANDA-REINTEGRAR-PECA-POLEMICA-GRADE-FESTIVAL-INVERNOGARANHUNS.aspx
} 
mídia e grandes corporações, quando decide e define sobre a exceção frente a interesses que vão constituindo "no corpo do direito, uma série de cesuras e divisões cujos termos são irredutíveis um ao outro, mas que, pela sua articulação e oposição, permitem que a máquina do direito funcione" (AGAMBEN, 2004, p.57). Outro tipo de choque, o contingenciamento de $47,5 \%$ da verba destinada à pasta da Cultura, que não chega a $1 \%$ do total da prefeitura, na cidade de São Paulo em 2017. Para que tal intervenção? É um gesto simbólico e ao mesmo tempo concreto: desmobilizar e promover o desmonte das políticas sociais e trabalhistas que até então foram conquistadas.

Foi por tudo isso que naquele 11 de dezembro não era só a dança de São Paulo que se faziam presentes. O Ato abriu com um vídeo que trazia imagens dos muitos acontecimentos envolvendo a dança e as artes em geral. Doze artistas que fazem parte do Movimento a Dança se Move estiveram à frente da organização: Carolina Callegaro, Clara Gouvêa, José Maria de Carvalho, Helena Bastos, Marcelo Pessoa, Ricardo Neves, Sandro Borelli, Solange Borelli, Tica Lemos, Vanessa Macedo, Vera Sala e Wellington Duarte. Sempre que artistas se reúnem para pensar atos/manifestos se discute qual deve ser o seu formato e, naquele momento, não foi diferente.

Decidimos começar ainda na rua e no hall de entrada do TUSP com um trecho da peça teatral $O$ Canto das Mulheres do Asfalto; ter dois apresentadores, caracterizados como tal, conduzindo o Ato de forma performática (inclusive com uma cena de nudez ao final); reunir falas ao microfone atravessadas por trechos de apresentações artísticas. Diferentes linguagens e segmentos tiveram seus espaços de fala: os artistas Alessandro Azevedo (circo), Célia Gouvêa e Wellington Duarte (dança); as professoras Helena Katz (Artes do Corpo - PUC) e Dulce de Aquino (Escola de Dança da UFBA); o produtor cultural José Renato; o vice-presidente da Cooperativa Paulista de Teatro, Thiago Vasconcelos; o presidente do SATED, Dorberto Carvalho; dois dos criadores das Leis de Fomento à Dança e ao Teatro, o deputado estadual José Américo e o ex-secretário de cultura da cidade de São Paulo, Nabil Bonduk; o ex-deputado e ex- 
presidente da Comissão da Verdade do Estado de São Paulo, Adriano Diogo; os vereadores Antônio Nonato e Juliana Cardoso e o ex-secretário de Cultura da cidade de São Paulo, Carlos Augusto Calil.

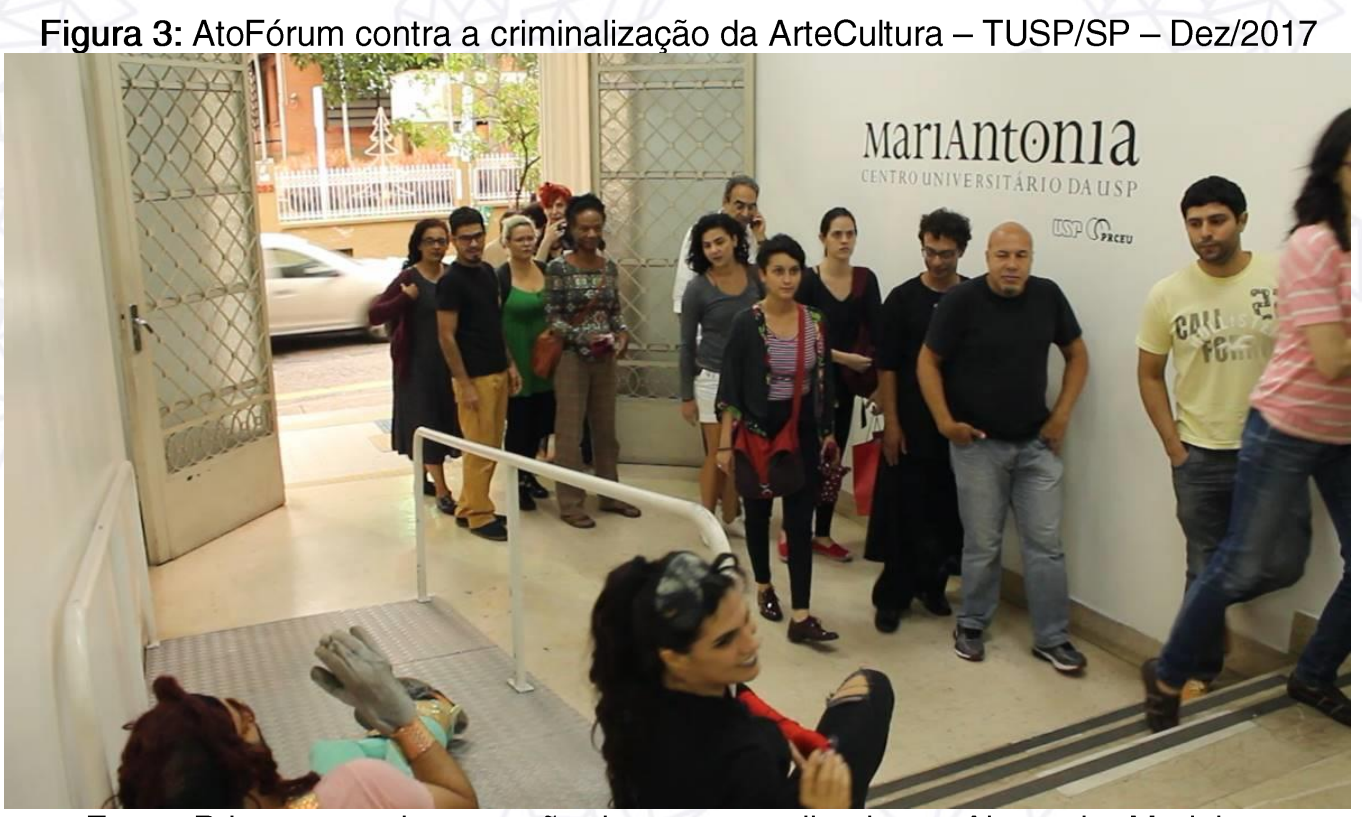

Fonte: Print screen da gravação do evento realizada por Alexandre Medeiros

Nos atravessamentos das falas tivemos a atriz e feminista Martinha Baião e um trecho do trabalho Colônia Penal, da Cia Carne Agonizante, inspirado no conto homônimo de Franz Kafka e na ditadura militar brasileira. Logo após essa última apresentação, um dueto no qual um bailarino agride o corpo da bailarina com atos de tortura, ouve-se uma manifestação da plateia. Uma mulher indigna-se e fala em voz alta que não devemos aplaudir aquela cena brutal, que a tortura aconteceu de fato no Brasil e não podemos reproduzi-la daquela maneira. Aquele acontecimento nos diz sobre a importância do encontro - manifestações artísticas sendo livres para produzirem os seus dissensos, gerando debate, promovendo experiências de alteridade.

É impossível ignorar o gesto daquela mulher. De modo incisivo, revela também nossa contradição, expor a tortura sem ter sido torturado. Aquele grito, também nos atingiu como um golpe. Foi imprevisto, mas produziu no AtoFórum a percepção de como distintas camadas nos envolvem, nos atravessam, nos implicam e nos movem. Que sejam temporalidades 
pontuais, mas aquele grito naquele contexto redimensionou, em parte, algumas de nossas bandeiras de lutas. Neste caso, falar de tortura, encenar tortura carregam pesos distintos daquele que viveu a própria tortura. São espaços próximos, mas distintos. E precisamos olhar estas diferenças com muito cuidado. Talvez seja este cuidado em relação ao próximo, naquilo que nos difere, que precisamos entender e respeitar como construir proximidades. A mulher precisou gritar e a Cia Carne Agonizante precisou dançar. Ambos nos remetem à tortura, um é ficção e outro ainda é ferida aberta, muito aberta e exposta.

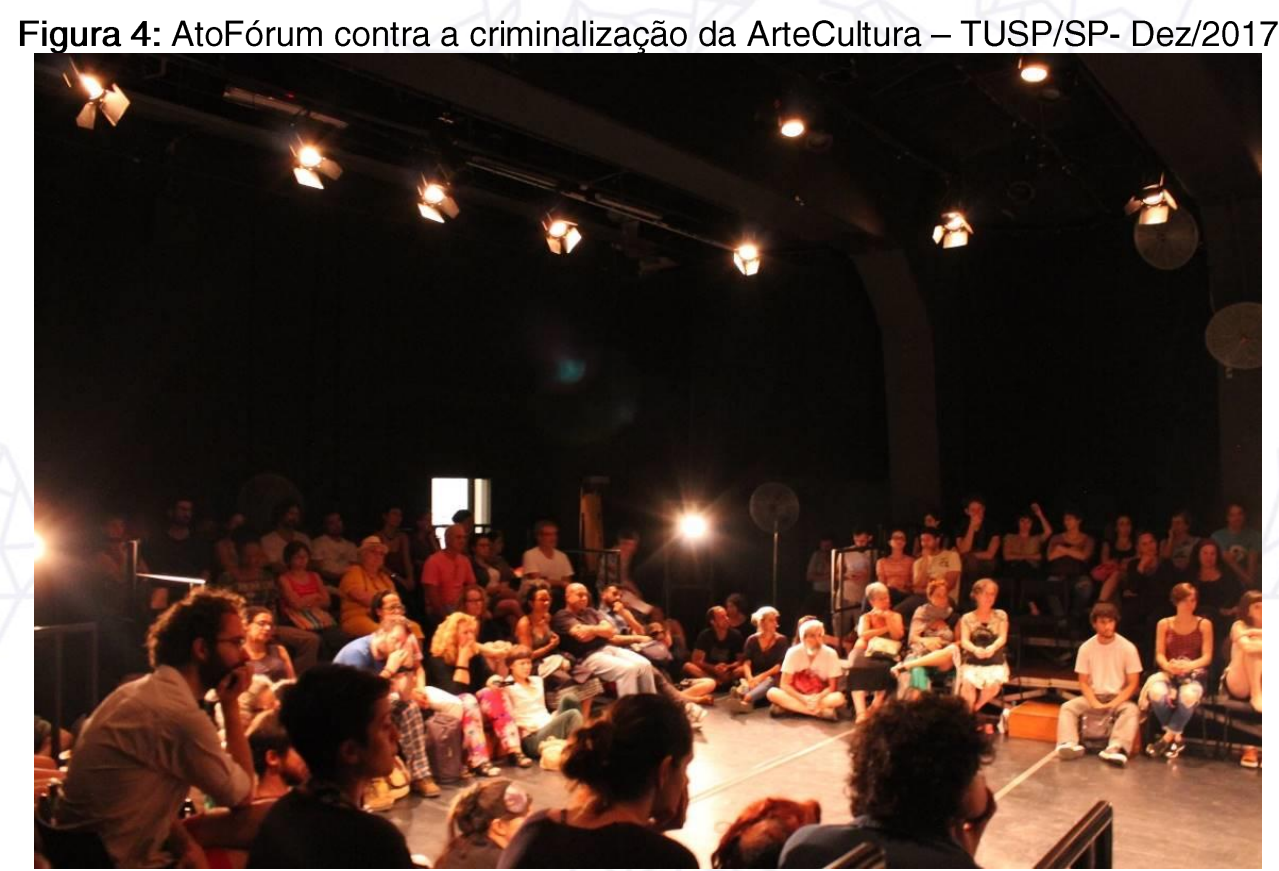

Foto: Alexandre Medeiros

Para além de uma retrospectiva dos fatos que marcaram o desmonte da Cultura naquele ano, aquele "AtoFórum" dizia sobre um desejo de furarmos a "bolha", uma discussão que se fazia recorrente nos encontros do movimento. Como criar espaços de visibilidade? Como nos mantermos juntos frente ao individualismo e à anestesia que pertencem ao mundo neoliberal? Como diz Tiburi, "o princípio de morte do capitalismo, sua capacidade de destruição relaciona-se com a lógica da avareza" (TIBURI, 2017, p.11). Apesar da percepção de que naquele encontro, falamos de nós para nós, pois ali não tínhamos discursos antagônicos, precisávamos 
construir e pensar sobre modos de permanecer. Que sejam temporalidades provisórias de convivências possíveis.

Figura 5: Tica Lemos e Marcelo Pessoa. AtoFórum contra a criminalização da ArteCultura Local: TUSP/SP - Dez/2017

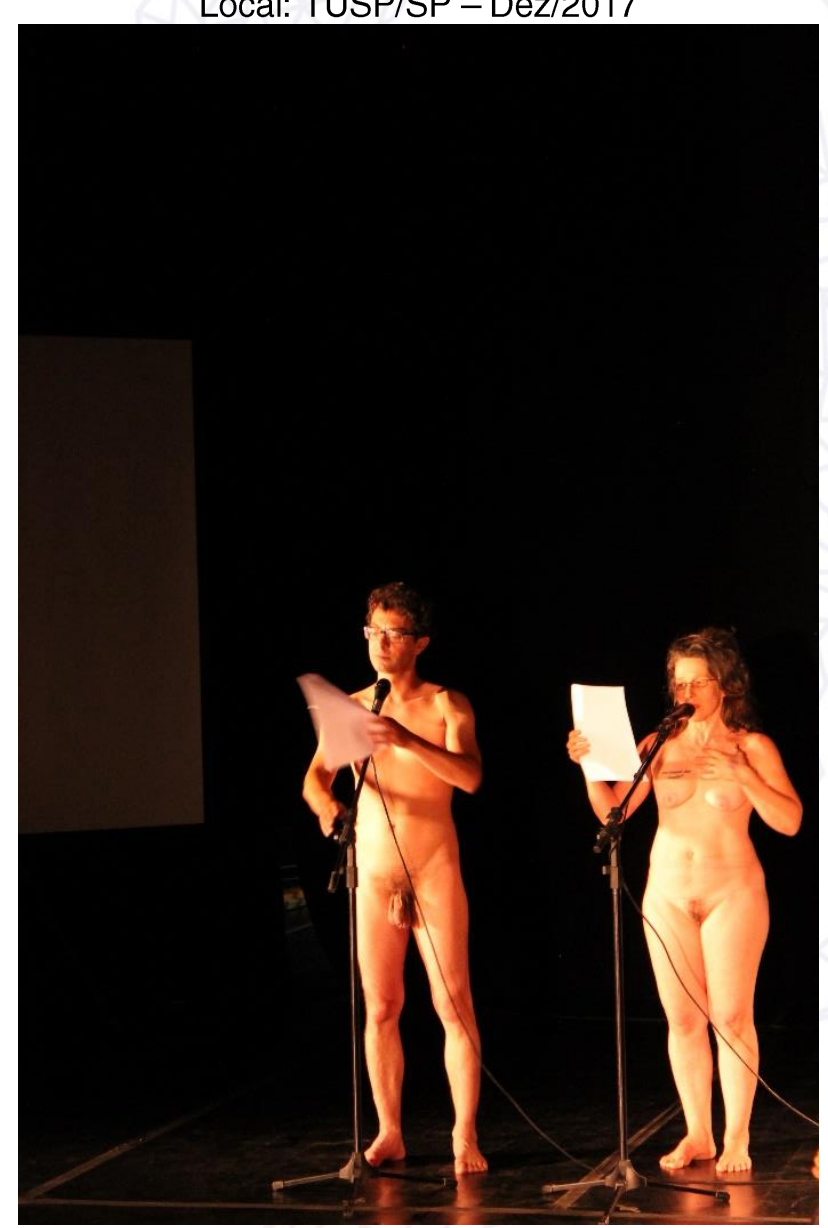

Foto: Alexandre Medeiros

\section{Breves Palavras}

É em sua própria materialidade que a dança evidencia suas potencialidades, mas expor neste trânsito gestos que redimensionem possibilidades de estarmos juntos, mesmo que nas assimetrias, é promover deslocamentos que, em seu percurso, expandem possibilidades de ação. Cada um tem algo diferente a oferecer. Desse modo, o Movimento a Dança se Move opera enquanto ponto de encontro político/estético de artistas da dança contemporânea, conforme pontuado anteriormente, que exercitam a construção de possibilidades de pensar políticas culturais estruturantes entre 
outros fatos que dizem respeito às artes no Brasil. Nessa lógica, elaborar o AtoFórum contra a criminalização da ArteCultura foi uma necessidade sentida por todos os envolvidos e por todas as envolvidas neste contexto.

Vivemos tempos de situações incertas e muitas vezes as singularidades, que também podem ser grupos, isolam a si mesmos. $O$ Movimento a Dança se Move e o Atofórum estabeleceram no tempo um encontro, uma provisoriedade tênue, que apesar de todos os percalços comungaram um instante potente na provocação e elaboração de reflexões frente ao desmonte e retrocesso que a arte e cultura vem sofrendo nos últimos anos no Brasil. Neste fim, cabe chamar para a ditadura criativista que nos é imposta. Povoamos um tempo em que a ideia de criativo vai sendo contaminada por um modo de operar criativista. Antes, chamamos atenção para aquilo que compreendemos como um sujeito criativo, em que simultaneidades são expostas entre fluxos de imaginação e sensos de realidade. Tais instâncias caminham lado a lado. Vislumbra-se nessas fricções uma instância política na criatividade por intervir criticamente na cultura. De modo distinto, o capitalismo criativo e o neoliberalismo capturam o termo "criatividade" do campo das artes. Nesta fisga, o receio de desgaste e erro direciona o capitalismo criativo a cercar uma ação criativa de modo mais medíocre e controlador. Cada vez mais somos cercados de atribuições mensuráveis quantificadoras que não dão conta de estratégias qualitativas as quais demandam em geral, mais tempo, além de outros riscos. Por isso, devemos ficar atentos para a ditadura criativista:

\footnotetext{
Então, algo fundamental para que alguém seja realmente criativo é roubado da pessoa criativista; a saber, o êxodo temporário de uma cultura ou de uma existência que é vista como real. Essa proibição de deslocamento assegura que o indivíduo criativista não possa fazer nada além de empurrar e puxar um pouco os limites de sua própria cultura - neoliberal - sem ser realmente criativo, revolucionário ou vertical. $O$ capitalismo criativo, que vê sua própria cultura como criativa ou, pelo menos, tenta proclamá-la como a moral dominante, não tem outro objetivo além de romper com a dialética entre cultura e criatividade. (GIELEN, 2015, p. 102)
}

Nessa perspectiva, precisamos estar vigilantes à lógica da indução criativista. O capitalismo criativo age de forma ferrenha nos impondo um 
empenho que aos poucos transforma o gesto criativo em gesto criativista. Precisamos captar essa armadilha, quando a veemência na criatividade vira criativismo. Por isso, "o homem criativista pode permanecer pisando em água para sempre no mundo plano e úmido". (GIELEN, 2015, p.102). No contexto artístico-cultural-social vivemos o excesso de determinação de produções inúteis. Como enfrentar esta lógica? Este texto é uma primeira reflexão. Acreditamos que virão outros desdobramentos. Dobras de um tecido vasto, que cada dobradura ambígua começa numa nuvem de possibilidades.

\section{Referências bibliográficas}

AGAMBEN, Giorgio. A Comunidade que vem. Tradução e notas Cláudio Oliveira. Belo Horizonte: Autêntica Editora, 2013.

AGAMBEN, Giorgio. Estado de Exceção. Tradução de Iraci D. Poleti. 2.ed. São Paulo: Boitempo, 2004.

BASTOS, Helena. Corpo sem vontade = Cuerpo sin voluntad. Revisão e tradução: Martina Altalef. São Paulo: ECA/USP: Cooperativa Paulista de Dança, 2017. DOSSIÊ Arte Sobre Coerção: moralismo privado no espaço público. Cult: Revista Brasileira de Cultura, ano 20, n. 230, dez. 2017.

GIELEN, Pascal. Criatividade \& Outros fundamentalismos. São Paulo: Annablume, 2015.

\section{Páginas consultadas:}

A DANÇA se move. Blog. Disponível em: http://dancasemove.blogspot.com. Acesso em: 11 jun. 2018.

CPI aprova condução coercitiva de artista e de curador de exposição. Senado Notícias. 8 nov. 2017. Disponível em:

https://www12.senado.leg.br/noticias/materias/2017/11/08/cpi-aprova-conducaocoercitiva-de-artista-e-de-curador-de-exposicao. Acesso em: 11 jun. 2018.

KLEIN, Naomi. A doutrina do choque: O tema do novo livro da ativista Naomi Klein. Adital, entrevista, Instituto Humanitas Unisinos. 30 set. 2007. Disponível em: 
http://www.ihu.unisinos.br/176-noticias/noticias-2007/562784-a-doutrina-do-choqueo-tema-do-novo-livro-da-ativista-naomi-klein. Acesso em 11 jun. 2018.

MOBILIZAÇÃO DANÇA. Blog. Disponível em:

http://mobilizacaodanca.blogspot.com. Acesso em: 11 jun. 2018.

MORAES, Eduardo Carli de. Capitalismo à la Pinochet: O neoliberalismo latinoamericano segundo Naomi Klein em "A Doutrina do Choque". In blog A casa de vidro. 31 jan. 2016. Disponível em:

https://acasadevidro.com/2016/01/31/capitalismo-a-la-pinochet-naomi-klein-revelaos-meandros-da-doutrina-do-choque/. Acesso em 9 jul. 2018.

O PREFEITO de São Paulo João Doria condena mostra 'Queermuseu' e performance no MAM. Publicado por Walisson Nascimento. (2min) 30 set. 2017. Disponível em: https://www.youtube.com/watch?v=2fkKQaKUjZQ. Acesso em: 11 jun. 2018.

PEÇA "O Evangelho Segundo Jesus, Rainha do Céu" é cancelada no Festival de Inverno de Garanhuns. G1 Caruaru e região. 1 jul. 2018. Disponível em:

https://g1.globo.com/pe/caruaru-regiao/noticia/peca-o-evangelho-segundo-jesusrainha-do-ceu-e-cancelada-no-festival-de-inverno-de-garanhuns.ghtml. Acesso em: 11 jun. 2018.

SCHWARTZ, Wagner. Fui morto na internet como se fosse um zumbi da série The walking Dead. In EI Pais: Opinião. Entrevista concedida a Eliane Brum. 12 fev. 2018. Disponível em: https://brasil.elpais.com/brasil/2018/02/12/opinion/1518444964_080093.html. Acesso em: 7 jul. 2018. 